J. Clin. Chem. Clin. Biochem.

Vol. 28, 1990, pp. $91-94$

(C) 1990 Walter de Gruyter \& Co.

Berlin · New York

\title{
Simultaneous Determination of Urinary Phosphate and Sulphate by Ion-Chromatography
}

\author{
By A. Claßen, W.-D. Miersch and A. Hesse \\ Experimentelle Urologie, Urologische Universitätsklinik Bonn, FRG
}

(Received December 2, 1988//July 14/October 19, 1989)

Dedicated to Prof. Dr. W. Vahlensieck on the occasion of his 60th birthday

\begin{abstract}
Summary: An ion-chromatographic system was used for the simultaneous determination of urinary phosphate and sulphate. This method was compared with conventional methods (colorimetric, turbidimetric) with regard to practicability and reliability. All methods showed good precision and accuracy. The comparative analysis of phosphate in 80 samples revealed that both methods lead to identical results. However, in case of sulphate a significant difference of about $8 \%$ was found between the two methods. Overestimation of the analyte concentration by the turbidimetric method might be responsible for this difference. From the point of view of economy, routine analysis of urinary phosphate and sulphate by ion-chromatography is acceptable only if automated systems are used.
\end{abstract}

\section{Introduction}

Research laboratories studying urolithiasis often determine the concentration of urinary phosphate and sulphate. The importance of determining phosphate seems to be evident, as phosphate is a frequent component of urinary concrements. Furthermore the inhibitory effect of orthophosphate on calcium urolithiasis has often been discussed. The significance of sulphate for the lithogenesis is hardly known and requires further attention. The few studies on the renal excretion of sulphate in stone patients and normals have produced different results $(1-3)$. A slight, positive effect of sulphate on the relative supersaturation of urine with calcium oxalate (sulphate forms soluble complexes with calcium) can be derived from Finlayson's calculations (4).

This work was undertaken to determine the extent to which modern ion-chromatography is of use for the quantitative analysis of urinary phosphate and sulphate. This question is particularly relevant, as ionchromatography is now established as a reliable method for the determination of oxalic acid, the most important lithogenous substance of human urine.
Many laboratories therefore already have the necessary equipment. The new method was compared with well-known conventional methods with respect to reliability and practicability.

\section{Ion-chromatography}

We used a chromatographic system which is used in this and other laboratories for oxalate analysis $(5,6)$. It consists of a system 2000i (No. 35200, Dionex Deutschland GmbH, D-6108 Weiterstadt, FRG) with an MPICE-NG1 precolumn (No. 35320), an HPICAS4 ion-exchange separator column (No. 35311) and an AFS suppressor column (No. 35350). An inlinefilter unit (No. 35331) was installed between the injection valve and the precolumn. The standard eluent (Dionex system) for anion separation was used as the mobile phase, i.e. a carbonate buffer containing 2.25 $\mathrm{mmol} / 1 \mathrm{NaHCO}$ and $2.80 \mathrm{mmol} / 1 \mathrm{Na}_{2} \mathrm{CO}_{3}$. The flow rate was $2.0 \mathrm{ml} / \mathrm{min}$. The regenerant was $12.5 \mathrm{mmol} / \mathrm{l}$ $\mathrm{H}_{2} \mathrm{SO}_{4}$ with a flow rate of $2.5 \mathrm{ml} / \mathrm{min}$. The conductivity detector was set to $10 \mu \mathrm{S}$ full scale. Peak areas were calculated by an integrator (CI-10, LDC-Milton Roy Deutschland GmbH, D-6467 Hasselroth, FRG). 
Five aqueous standards $(5-40 \mathrm{mmol} / \mathrm{l})$ containing sodium phosphate $\left(\mathrm{NaH}_{2} \mathrm{PO}_{4} \cdot 2 \mathrm{H}_{2} \mathrm{O}\right)$ and sodium sulphate $\left(\mathrm{Na}_{2} \mathrm{SO}_{4}\right)$ were used for calibration and prepared freshly. For the preparation of the samples, $1 \mathrm{ml}$ of urine or standard was diluted with $1 \mathrm{ml}$ of 0.5 $\mathrm{mol} / \mathrm{l} \mathrm{HCl}$, then after one hour demineralized water was added to give a volume of $200 \mathrm{ml}$. This solution $(50 \mu l)$ was injected.

\section{Photometric methods}

As comparative methods we used the phosphomolybdate method (Merckotest No. 3331, E. Merck, D6100 Darmstadt, FRG) to determine phosphate and the turbidimetric barium sulphate method (Berglund \& Sörbo, (7)) to determine sulphate.

\section{Studies of method control}

Within-run imprecision was estimated by analysing 3 urinary samples of the lower, middle and upper range of concentration 20 times each. Total imprecision was calculated by analysing 3 urinary samples in duplicate $(a, b)$ on ten successive working days, the coefficient of variation being calculated from the b-values. To rate the absolute accuracy of our methods 20 random urinary samples were spiked with $6 \mathrm{mmol} / 1$ of phosphate and sulphate. Both basic and spiked samples were analysed four times, and the mean concentrations were used to calculate the percentage of recovery. The determination of 80 different urinary samples should also provide a basis for comparison of the accuracies of the methods.

\section{Results and Discussion}

A typical chromatogram is shown in figure 1. Phosphate and sulphate are well separated from other urinary components and we did not observe any interference from other organic or inorganic compounds throughout this study. The retention time is about 3 minutes for phosphate and 7.2 minutes for sulphate. It is slightly reduced when the working period of the column increases, probably because active sites of the separator column are blocked by irreversibly adsorbed components of the samples. However, as the samples are very dilute, the contamination of the column is a rather slow process. The column we used did not show any decrease in chromatographic efficiency after the analysis of 2700 samples, which does not support the view of Pei \& Vonderschmitt (8), that the main disadvantage of ionchromatography is the rapid deterioration of the column efficiency. Certainly the precolumn, which was

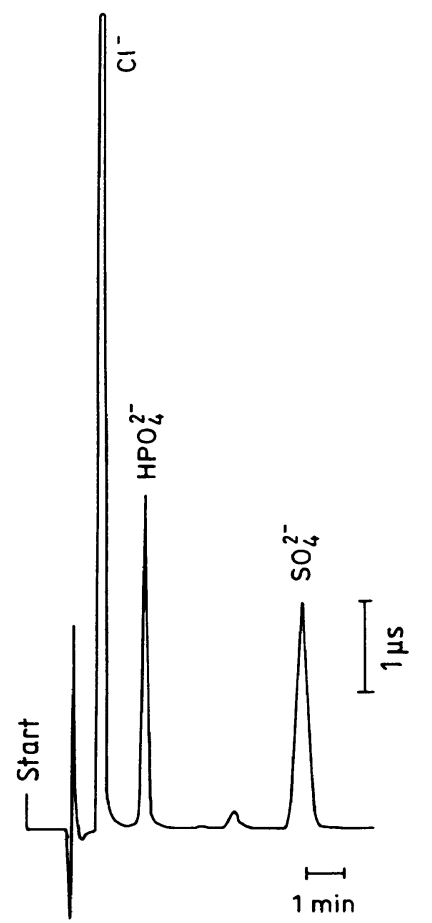

Fig. 1. Simultaneous chromatographic determination of urinary phosphate and sulphate; $15 \mathrm{mmol} / \mathrm{l}$ each, before dilution.

exchanged after every 500 samples, contributed to this result. The use of the inline-filter turned out to be very useful, as we did not need to clear each sample and could dispense with expensive disposable membrane filter units. Despite the fact that samples were not cleared prior to analysis, blockage of the injection system did not occur.

The colorimetric or turbidimetric as well as the ionchromatographic method for the determination of phosphate and sulphate revealed a linear relationship between detector response and concentration of the analytes in the relevant range from 5 to $40 \mathrm{mmol} / \mathrm{l}$. In the chromatographic method acidification of the sample did not affect the peak of phosphate. Thus, the hydrochloric acid, resulting from the suppressor reaction, did not influence the dissociation of the phosphoric acid in the concentrations used.

In the determination of phosphate, the within-run imprecision was between 2.0 and $2.7 \%$ for the ionchromatographic method (IC) and between 0.9 and $3.1 \%$ for the colorimetric method. The values for sulphate were between 2.2 and $3.1 \%$ (IC) or 0.6 and $3.9 \%$ (turbidimetry). The total imprecision for phosphate was between 1.6 and $4.8 \%$ (IC) and between 2.2 and $4.4 \%$ (colorimetry). For sulphate the corresponding values were between 1.7 and $4.9 \%$ (IC) and between 2.2 and $7.3 \%$ (turbidimetry) (tab. 1). 
Tab. 1. Quality control data of different methods for the determination of urinary phosphate and sulphate.

\begin{tabular}{llllll}
\hline & \multicolumn{2}{l}{ Phosphate } & & \multicolumn{2}{c}{ Sulphate } \\
\cline { 2 - 3 } & chromatographic & colorimetric & & chromatographic & turbidimetric \\
\hline Within-run imprecision, CV (\%) & $2.0,2.4,2.7$ & $0.9,1.1,3.1$ & & $2.2,2.7,3.1$ & $0.6,1.8,3.9$ \\
Total imprecision, CV (\%) & $1.6,3.2,4.8$ & $2.2,4.4,4.4$ & & $1.7,3.4,4.9$ & $2.2,4.1,7.3$ \\
Recovery (\%) & 100.1 & 99.0 & 100.3 & 104.4 \\
\hline
\end{tabular}

The mean recovery was $100.1 \%$ (IC) $/ 99.0 \%$ (colorimetry) for phosphate and $100.3 \%$ (IC)/104.4\% (turbidimetry) for sulphate (tab. 1).

The results of 80 determinations of phosphate with both methods are shown in figure 2 . The evaluation according to Passing \& Bablok (9) revealed that statistically both methods lead to identical results. For sulphate (fig. 3), however, the two methods gave different results, since the intercept of the regression line was significantly different from 0 . On average, the values of the chromatographic method were about $8.2 \%$ lower than those of the turbidimetric method. We think that this difference might be explained by an overestimation of the sulphate concentration by the turbidimetric method. Neither the phosphate concentration nor the occurrence of proteinuria seem to be responsible for this overesstimation. The coefficient of correlation between the differences of the sulphate concentrations and the corresponding concentration of phosphate was only 0.25 . Thus, only $5 \%$ of the variance could be explained by the variance of the phosphate concentration. Furthermore, proteinuria was not present in any of the urine samples.

It seems more likely that an unspecific light absorption by urinary pigments is responsible for the difference we discovered. If - contrary to the protocol of Berglund \& Sörbo - a sample blank was used, the measured sulphate concentration dropped significantly by about $5 \%$ (data not shown). This, as well as the mean recovery rates of both methods, seems to indicate that ion-chromatography leads to more accurate results. To what extent, however, a difference of less than $10 \%$ between the two methods will be regarded as important depends both on the demands of the analyst and the clinical validity of the parameter.

All methods mentioned here are easy to perform. Using the colorimetric (phosphate) or the turbidimetric (sulphate) method it is possible to analyse phosphate and sulphate in a hundred samples per technician per day. By ion-chromatography 40 samples can be analysed per day; a constant presence of attendants is also necessary. With regard to labour costs, ion-chromatography is therefore 2.5 times more expensive than the conventional methods. As far as costs of material are concerned, the photometric methods are also cheaper than the ion-chromatographic method. However, all these calculations concerning the economy of the chromatographic method are only valid for the manually operated system used here.

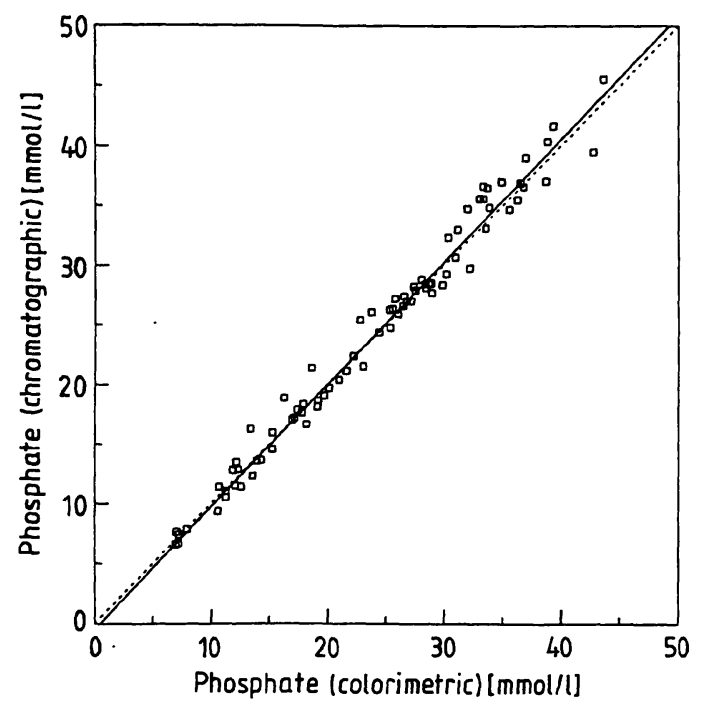

Fig. 2. Comparative determinations of phosphate: chromatographic method versus colorimetric method. Function $\mathrm{y}=\mathrm{x}($ dotted $)$ and regression line $(\mathrm{y}=1.024 \mathrm{x}-0.395)$. $\mathrm{n}=80$

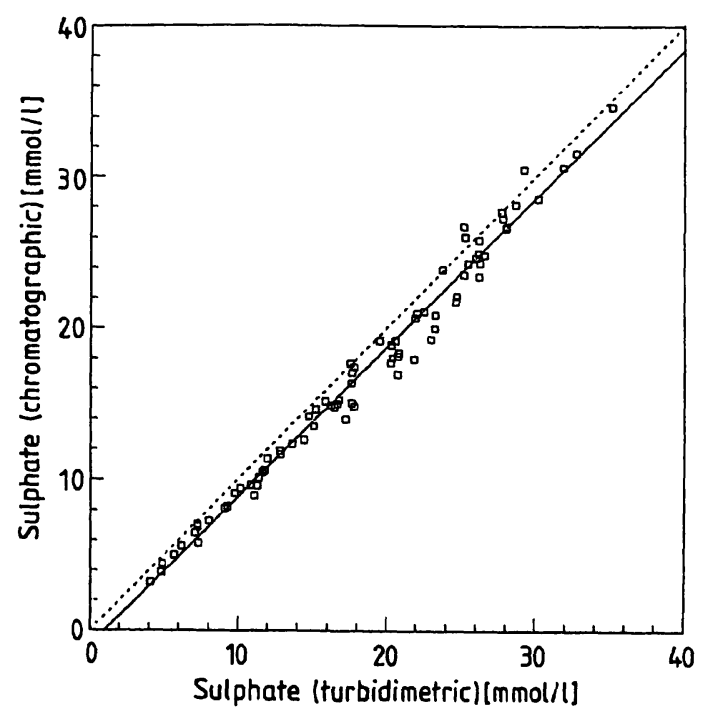

Fig. 3. Comparative determinations of sulphate: chromatographic method versus turbidimctric method. Function $y=x$ (dotted) and regression line $(y=0.985 x-0.993)$. $\mathrm{n}=80$ 


\section{Conclusion}

Our results lead to the following conclusion: the ionchromatographic method allows the simultaneous determination of urinary phosphate and sulphate and leads to precise and accurate results. For economical reasons, however, it seems only to be useful for the laboratory routine when fully automated systems (autosampler, computer-aided data analysis) are applied.

\section{References}

1. Hamper, A., Hanisch, E., Schwille, P. O. \& Sigel, A. (1984) Urin-Sulfat bei Calcium-Urolithiasis. In: Pathogenese und Klinik der Harnsteine, X. (Vahlensieck, W. \& Gasser, G., eds.) Steinkopff, Darmstadt, pp. 83-86.

2. Robertson, W. G., Peacock, M. \& Nordin, B. E. C. (1968) Activity products in stone-forming and non-stone-forming urine. Clin. Sci. 34, 579-594.

3. Schaefer, R. M., Hesse, A., Klocke, K. \& Vahlensieck, W. (1986) Untersuchungen zur Sulfatausscheidung im Urin von Gesunden und rezidivierenden Calciumoxalatsteinbildnern. In: Pathogenese und Klinik der Harnsteine, XII. (Vahlensieck, W. \& Gasser, G., eds.) Steinkopff, Darmstadt, pp. 76-80.

4. Finlayson, B. (1977) Calcium stones: Some physical and clinical aspects. In: Calcium metabolism in renal failures and nephrolithiasis (David, D. S., ed.) John Wiley \& Sons, New York London Sydney Toronto, pp. 337-382.

5. Classen, A. \& Hesse, A. (1987) Measurement of urinary oxalate: An enzymatic and an ion chromatographic method compared. J. Clin. Chem. Clin. Biochem. 25, 95-99.
The simultaneous determination of urinary oxalic acid is then also possible.

\section{Acknowledgement}

This investigation was supported by the Doktor-Robert-Pfleger-Stiftung. The authors wish to thank Miss E. Zerbin for her valuable technical assistance.
6. Robertson, W. G., Scurr, D. S. \& Sergeant, V. J. (1985) Prevention of ascorbic acid interference in the measurement of oxalic acid in urine by ion chromatography. Clin. Chim. Acta 140, 97-99.

7. Berglund, F. \& Sörbo, R. (1960) Turbidimetric analysis of inorganic sulphate in serum, plasma and urine. Scand. J. Clin. Invest. 12, 147-153.

8. Pei, P. \& Vonderschmitt, D. J. (1987) Simultaneous determination of chloride, sulphate, orthophosphate and organic anions in human urine by capillary isotachophoresis. J. Clin. Chem. Clin. Biochem. 25, 253-259.

9. Passing, H. \& Bablok, W. (1983) A new biometrical procedure for testing the equality of measurements from two different analytical methods. Application of linear regression procedures for method comparison studies in clinical chemistry, Part I. J. Clin. Chem. Clin. Biochem. 21, 709-720.

\author{
Professor Dr. rer. nat. A. Hesse \\ Experimentelle Urologie \\ Urologische Universitätsklinik \\ Sigmund-Freud-Straße 25 \\ D-5300 Bonn 1
}

